\title{
Research of the Differentiated Development of Taiwan's Police Education
}

\author{
Zhiqiu Yang and Liqu Song
}

Department of Foundation of Public Safety, China's Criminal Police College, Shenyang, Liaoning, 110035; Department of Organizational Personnel, China's Criminal Police College, Shenyang, Liaoning, 110035

Chongqing Municipality, 401320

\begin{abstract}
Police education is the very source of force construction, the basic guarantee of improving police force's strength and the great importance that all countries attach to the development of police education. Both the mainland's and Taiwan's police educations are the inheritance and continuity of early modern China's police education, and they all have headed for their own ways during the developing process. Mainland's police education, however, especially their degree education, starts comparatively late, and the according legal system is still not well-developed enough; the task partitioning between educational institutions of ministry and provinces are not clear enough, and there are problems like repetitious construction and insufficient mutual complementation in police education and so on. Police education in Taiwan, adopting the educational pattern of combining degree(cultivating) education and in-service police training, is of clear school-running hierarchy and clear-cut task partitioning as well as standard teaching settings, realizing the effective bridging between police educational mechanism and police matriculation system. The differentiated developing patterns of Taiwan's police education plays an important role in fully utilizing police teaching resources, boosting characteristic development of police reaching, promoting the professional training of police and so on.
\end{abstract}

Keywords: Taiwan; Police education; Diversity, Development; Exploration

\section{台湾警察教育的差异化发展探究}

\author{
杨志秋, 宋立渠
}

(中国刑事警察学院公安基础部 辽宁 沈阳 110035; 中国刑事警察学院组织人事处 辽宁 沈阳 110035 )

摘要: 警察教育是警察队伍建设的源头, 是提升警察队伍实力的基本保障, 基本保障各国都极其重视警察教育事业的发 展。大陆和台湾警察教育都是对中国近代警察教育的继承和延续, 并在发展过程中形成了各自的道路。但是, 大陆警察教育 尤其是警察学历教育起步较晚, 相应的法律制度体系尚不够健全, 部、省两级教育机构之间的任务分工不够清晰, 警察教育 既存在重复建设又存在相互补充不足等问题。台湾警察教育采用学历 (养成) 教育与在职警察培训相结合的教育模式, 警察 教育办学层次清晰, 任务分工明确, 教学设置规范, 且实现了警察教育机制与警察考录制度的有效衔接。台湾警察教育的差 异化发展模式在充分利用警察教育资源, 促进警察教育特色发展, 提升警察专业培养能力等方面发挥了重要作用。

关键词: 台湾; 警察教育; 差异化; 发展; 探究

\section{1 台湾警察教育差异化发展的基本情况及其特点}

台湾警察教育立法较为全面, 不仅有宏观层面的法律规定, 而且还有微观层面的规章制度, 形成了较 为完备和系统的警察教育法律制度体系。首先, 台湾警察法规定由台湾警察大学 (以下简称为警大) 和台 湾警察专科学校 (以下简称为警专) 承担台湾警察教育职责。其次, 在根据台湾警察法制定的《警察教育 条例》中, 对警察教育模式、师资队伍要求以及课程计划等方面作了相关规定。在警察教育模式方面, 条 例中规定, 警察教育存在三种模式, 即养成教育、进修教育和深造教育。对于养成教育的培养任务在警专 和警大之间进行了明确分工，警专承担专科层次的警察教育，培养面向一线执法执勤岗位的基层警员；警 
大承担四年制本科层次的警察教育以及两年制技术班 (相当于大陆警察在职人员的二学位教育), 并开设 研究所教育 (即开展硕士、博士研究生教育)。同时, 条例第 6 条规定, 由警大办理在职警察人员进修教 育中的警佐班、专业班, 以及在职警察人员深造教育中的警监、警正班和研究班（在台湾地区, 警察职级 划分为警监、警正和警佐三级，每一级内又分为四等)。此外，根据《警察教育条例》第 6 条规定制定的 《警察人员进修及深造教育实施办法》中又对进修教育和深造教育的类别及其教育期限作了详细规定, 并 规定了进修教育中的巡佐班和专业班由警专负责（台湾警察局的巡佐职务相当于派出所正、副所长职务）。 根据《警察教育条例》, 又分别制定了《台湾警察大学组织条例》和《台湾警察专科学校组织条例》, 分别 对警大和警专的行政机构及人员设置、师资队伍建设等内容做了不同的规定。在师资队伍建设上，《台湾 警察大学组织条例》和《台湾警察专科学校组织条例》分别对警大和警专的教授、副教授、助教和讲师的 师资队伍组成以及教官的职级和数量作了不同的规定。台湾警察教育健全的规范体系在法规层面对台湾警 察院校的办学定位、教育任务分工、师资队伍建设等方面作了明确的规定, 为台湾警察教育的差异化发展 提供了法律保障。

\section{2 台湾警察教育的差异化发展对大陆警察教育的启示}

\section{1 建立完善的警察教育法律制度体系}

规范大陆警察教育，首先应当完善大陆警察教育的法律制度体系，保证警察教育在立校、办学以及教 育培训等方面能够有法可依, 促进警察教育教学的法制化和规范化。台湾警察法中规定了由警大和警专承 担警察教育任务。《警察教育条例》中又对警察教育模式以及师资队伍建设等内容作了规定。此外，《台湾 警察大学组织条例》和《台湾警察专科学校组织条例》及警大和警专的 “办事细则” 对两所警校的内部教 学机构、人事编制以及师资队伍建设等内容作了更具体的规定。与台湾相比, 大陆警察教育法律制度建设 相对滞后, 涉及警察教育的法律制度要么体系不够完善, 要么过于笼统宽泛。大陆虽然在法律制度方面对 警察教育的规定有所涉及, 但是较为笼统且尚未形成宏观与微观相结合的完善的法律制度体系, 例如, 《中 华人民共和国人民警察法》第 29 条对警察教育只做了笼统的规定：“国家发展人民警察教育事业，对人 民警察有计划地进行政治思想、法制、警察业务等教育培训。” 除此之外，大陆缺乏专门的 “警察教育条 例” ，对警察教育在立校、办学、教育机构设置、师资队伍建设以及警察教育与招录的衔接上没有专门的 规定，例如在《公安机关组织管理条例》中，对警察院校的组织性质、警校人员编制、职务序列以及对警 察院校毕业生的录用问题没有作出相应的规定。建立和完善大陆警察教育法律制度体系，首先要提高大陆 警察教育的法律规范意识。其次是在法律制度框架内, 建立宏观及微观层面相结合的法律规范体系。在宏 观层面上, 在人民警察法或《公安机关组织管理条例》中, 对承担警察教育任务的警察院校的内部机构设 置及其在公安机关中的组织地位、职务序列、警察院校毕业生的入警考录制度进行统一规范; 在微观层面 上，制定专门的 “警察教育条例” ，对警察院校在办学层次、教育模式、内部教学机构设置以及人员编制 等方面作具体的规定。

\section{2 明确警察教育机构的办学理念和目标}

警察院校的办学理念是警察院校发展的灵魂，其办学理念及办学目标具体指引着警察院校的实际发 展, 对警察教育产生多方面的影响。大陆警察教育发展趋向同质化, 各警察院校的办学理念、培养目标模 糊, 教学重复建设、职责交叉, 教育资源浪费, 不利于教育事业的发展。借鉴台湾警察教育的差异化发展 
模式, 大陆警察院校要明确自身的办学理念和教育培养目标, 为本校的警察教育模式选择和内部教学机构 的设置提供引导。确立警察院校办学理念和目标既要符合高校办学理念的一般规律, 又要充分考虑到警察 院校鲜明的政治性和警察教育自身的情况和特点。此外, 警察教育不能脱离社会实践的需要, 办学理念设 计不仅要考虑公安机关的人才需求, 还要考虑到社会发展、变化对警察教育的影响。大陆警察院校在建校、 办校过程中只有明确了自身的办校理念和目标, 才能为本校的教学单位设置和教育模式的选择提供引导, 在警察教育事业发展中形成自己的竞争优势和院校品牌。

\section{3 合理划分教学任务, 注重各警察院校的差异化建设}

我国大陆幅员广阔, 各地经济发展水平不一且各地都设有自己的警察院校, 而且在条块结合、以块为 主的警察管理体制下, 完全做到警察教育任务的明确分工不太现实。对于大陆警察院校特别是部属院校与 省属院校目前任务分工不够明确且存在交叉重复的问题, 虽已引起了有关部门的高度重视, 但具体落实工 作相对迟缓。2011 年公安部政治部印发的《关于改进和加强公安院校和训练基地建设工作的指导意见》 中指出 “部属本科院校负责培养高端专业人才及高层次、综合性的民警培训工作, 积极向教学研究型高校 迈进” ; “省属本科院校致力于培养实用性和应用型人才, 积极开展基层领导干部、业务骨干等民警培训 工作, 努力建成高质量的教学型高校”。在警察教育实践中要严格落实上述警察教学任务的分工, 并做到 部属和省属院校间的相互配合和交流, 促进警察教育资源的有效整合和高效运用, 避免对教育资源的浪费。 在专业设置上, 不同层级的警察院校之间应当体现差异化, 对于培养高水平公安专业人才的部属院校和培 养全面型公安专业人才的本科层次院校, 在专业设置涉及领域及研究深度上要与其培养高素质人才的目标 相适应。对于注重培养基层实战岗位公安人才的专科院校, 在专业设置上要符合其培养应用型、实战型人 才的需要。对于专门警种公安院校, 在专业设置上要注重体现其特色和优势。同时, 大陆警察教育缺乏通 识教育意识, 过分强调专业教育, 不利于警察人才的全面发展。大陆警察教育应增加人文社会科学课程, 设置专门机构, 配备专职教师, 在专业教育上也要体现通识教育的理念, 提升警察的人文素养和法治意识。 除此之外, 大陆警察教育要加强与警务实战部门的联系, 注重警务实战知识教育, 警察教育的教学方式和 内容不能只是对警务专业知识的发展历程、相关概念和原则等宏观基础理论的介绍, 还要联系警务工作的 现实发展情况以及实战一线部门具体的实践操作, 注重教学理论与警务实践的结合。

\section{4 注重师资专业及实务能力建设, 形成警察院校教师的 “双结构”}

台湾警大和警专师资队伍建设与其办学定位和培养目标相一致, 分别在专业教育和应用能力教育方面 有所侧重, 其共同点是都组建了 “双结构” 的教师队伍。教师队伍由专任教师以及教官共同组成, 兼顾了 警察专业教育和实战警务技能教育的要求。大陆警察院校的教师偏重于专业理论研究, 接触实战单位的机 会较少, 师资队伍中始终缺乏高深理论知识与宝贵实战经验兼具的 “双师型” 人才。大陆警察院校的师资 队伍建设可以借鉴台湾警察院校的师资队伍理念。一方面, 建立新型的警察院校教师考核评价机制, 鼓励 教师进入实战单位进行定期培训学习, 加强教师与警务实战单位的交流, 保障教学与警务实战接轨以及教 学理论、内容的不断更新; 另一方面, 加强警察院校教学与警务实战部门的双向沟通, 聘用警务实战部门 经验丰富或者具有某项警务专长的警察人员进入课堂, 开展专题、系列或情境教学。

\section{5 建立符合警务工作特点和警察职业能力需求的警察招录体制}

台湾警察院校毕业生通过台湾警察特考进入警察机关, 根据报考者的学历及报考职位的不同, 在考试 
等级及考试内容上有不同的要求, 并且体现了警察职业的特色和招考岗位的需要。大陆警察院校的毕业生 通过参加国家公务员或者各省公务员考试进入警察机关，与其他公务员考试相比，警察参加公务员考试在 考试科目上除了部分地区增加了公安基础知识科目以及对报考者进行体测外，总体上与其他公务员考试差 别不大, 没有体现警察招录的职业特色, 并且入警人员所从事的警务工作与其在校专业并不是完全对口, 导致警察教育资源的浪费，制约警察教育功能的发挥，不利于警察教育事业的发展。笔者认为，完善大陆 的警察招录体制, 可以借鉴台湾双轨分流的警察招录制度, 面向具有警察教育背景的人员和社会人员设置 不同的考试途径，并在考试内容和形式上有所区分。对具有警察教育背景的人员在招录考试的内容及形式 上加大对警察专业知识的考核, 以体现警察职业特点的要求, 促使警察院校学生在接受警察教育的过程中 能有所学, 学有所考, 考有所用。对考入警察机关的社会人员来说, 要注重对其进行有针对性的后期警察 职业培训。

台湾与大陆毕竟存在地域、政治、经济等多方面的差异，在借鉴台湾警察教育差异化发展模式的过程 中, 要善于发现并利用其中适合大陆警察教育的教育理念和教育模式, 弥补大陆警察教育及警察院校办学 中存在的缺陷, 促进警察教育事业的进步和发展。

\section{致谢:}

基金支持：本文系辽宁省高教学会“十三五”规划高教研究立项课题《国境外警察教育的差异化发展 及启示一一台湾地区、韩国、日本为例》，课题编号 GHYB160179 的阶段性研究成果。

\section{Acknowledgement:}

Fund Support: This essay is the fruit of phased research of the Higher Education Research Project Subject of Higher Education Association of "Thirteen Five" Plan of Liaoning Province--The Differentiated Development and Inspiration of Police Education at Home and Abroad--Taking Taiwan, Korea and Japan as Examples (Subject Number,GHYB160179)

\section{参考文献：}

[1] 陈明传． 警察百科全书(五) 警察学与警察行政[M]．台北:正中书局，2000． 36，280.

[2] 邱华君. 警察学[M] . 台北:千华出版公司, 1997. 116.

[3] 邱华君． 警察法规[M] . 台北：五南图书出版公司，1988． 566.

[4] 王离京. 台湾地区警察教育制度初考[J]. 山东警察学院学报, 2010，(1).

[5] 林忠志. 台湾地区司法运作机制研究[J].台湾法研究, 2006(4): 47.

[6] 于群, 杨志秋, 尚方剑. 台湾警察学校的通识教育及启示[J] . 湖北警官学院学报,2014(3): 174-177.

[7] 张俊海. 台湾地区警察教育训练的特色及其启示[J]. 山东警察学院学报,2014(3):76-83.

[8] 郏红雯. 大陆与香港、台湾地区警察教育训练之研究[J] . 辽宁警察学院学报, 2016(6): 87-91.

[9] 杨志秋, 于群. 台湾警察的特考制度及其分析评价 [J] . 河北公安警察职业学院学报, 2013(2): 71-76.

[10] 王和，郑群．台湾地区警察教育的概况及其启示 [J]．公安教育，2009(11)：68.

[11] 新华社. 赴台自由行 8 个月无人逾期滞留[N]. 东方早报, 2012-01-25.

\section{References:}

[1] Chen Mingchuan. Encyclopedia of Police (V) Police Science and Police Administration 
[M].Taipei: Cheng Chung Book Co., Ltd., 2000. 36, 280.

[2] Qiu Huajun. Police Science [M].Taipei: Chuan Hwa Publishing Ltd., 1997. 116.

[3] Qiu Huajun. Police Regulations [M].Taipei: Wu-Nan Book Inc., 1988. 566.

[4] wang Lijing. Preliminary Study on Police Education System in Taiwan [J].Journal of Shandong Police College, 2010, (1).

[5] Lin Zhongzhi. Research on Justice Operating Mechanism in Taiwan [J].The Journal of Research on Law in Taiwan, 2006 (4):47.

[6] Yu Qun, Yang Zhiqiu, Shang Fangjian. Police in Taiwan and Its Enlightenment of General Education in Schools [J].Journal of Hubei Universityof Police, 2014 (3):174-177.

[7] Zhang Junhai. Characteristics and Revelation of Police Education and Training in Taiwan [J].Journal of Shandong Police College, 2014 (3):76-83.

[8] Jia Hongwen. Study on Police Education and Training of Mainland and Hong Kong, Taiwan [J].Journal of Liaoning Police Academy, 2016(6):87-91.

[9] Yang Zhiqiu, Yu Qun. Evaluation and Analysis of Special Examination of Taiwan Police System [J].Journal of Hebei Vocational College of Public Security Police, 2013(2):71-76.

[10] Wang He, Zheng Qun. General Situation and Revelation of POLICE EDUCation in Taiwan [J].Police Education and Training, 2009 (11):68.

[11]The Xinhua News Agency. Travel Free for 8 Months in Taiwan without Overdue Detention [N].Oriental Morning Post, 2012-01-25. 